\title{
Differential impact of hotter drought on seedling performance of five ecologically distinct pine species
}

\author{
Luis Matías $\mathbb{D} \cdot$ Jorge Castro $\cdot$ Pedro Villar-Salvador • \\ José L. Quero • Alistair S. Jump
}

Received: 15 July 2016/Accepted: 3 November 2016/Published online: 9 November 2016

(C) The Author(s) 2016. This article is published with open access at Springerlink.com

\begin{abstract}
Increasing temperature and drought intensity is inducing the phenomenon of the so-called "hotter drought", which is expected to increase in frequency over the coming decades across many areas of the globe, and is expected to have major implications for forest systems. Consequences of hotter drought could be especially relevant for closely related species overlapping their distributions, since differences in response can translate into range shifts. We assessed the effect of future climatic conditions on the performance of five ecologically distinct pine species common in Europe: Pinus halepensis, $P$. pinaster, $P$. nigra, $P$. sylvestris and $P$. uncinata. We hypothesised
\end{abstract}

Communicated by Wayne Polley.

Electronic supplementary material The online version of this article (doi:10.1007/s11258-016-0677-7) contains supplementary material, which is available to authorized users.

L. Matías $(\bowtie) \cdot$ A. S. Jump

Biological and Environmental Sciences, School of Natural Sciences, University of Stirling, Stirling FK9 4LA, UK

e-mail: lmatias@irnas.csic.es

Present Address:

L. Matías

Instituto de Recursos Naturales y Agrobiología de Sevilla

(IRNAS-CSIC), Av. Reina Mercedes, 10, 41080 Seville, Spain

\section{J. Castro}

Departamento de Ecología, Facultad de Ciencias,

Universidad de Granada, Av. Fuentenueva SN,

18071 Granada, Spain that Mediterranean species inhabiting dry, low-elevation sites will be less affected by the expected warming and drought increase than species inhabiting cold-wet sites. We performed a controlled conditions experiment simulating current and projected temperature and precipitation, and analysed seedling responses in terms of survival, growth, biomass allocation, maximum photochemical efficiency $\left(F_{\mathrm{v}} / F_{\mathrm{m}}\right)$ and plant water potential $(\Psi)$. Either an increase in temperature or a reduction in water input alone reduced seedling performance, but the highest impact occurred when these two factors acted in combination. Warming and water limitation reduced $\Psi$, whereas warming alone reduced biomass allocation to roots and $F_{\mathrm{v}} / F_{\mathrm{m}}$. However, species responded differentially to warmer and drier conditions, with lowland Mediterranean pines ( $P$. halepensis and $P$. pinaster) showing higher survival and performance than mountain species.

\section{P. Villar-Salvador}

Forest Ecology and Restoration Group, Departamento de Ciencias de la Vida, Universidad de Alcalá, P.O. Box 20, 28805 Alcalá de Henares, Madrid, Spain

\section{J. L. Quero}

Departamento Ingeniería Forestal, Escuela Técnica Superior de Ingeniería Agronómica y de Montes, Universidad de Córdoba, Campus de Rabanales, Crta. IV, km. 396, 14071 Córdoba, Spain

A. S. Jump

CREAF, Campus de Bellaterra (UAB) Edifici C, Cerdanyola del Vallès, Spain 
Interspecific differences in response to warmer, drier conditions could contribute to changes in the relative dominance of these pine species in Mediterranean regions where they co-occur and a hotter, drier climate is anticipated.

Keywords Climate change - Ecophysiology · Growth $\cdot$ Pinus $\cdot$ Regeneration $\cdot$ Warming $\cdot$ Water potential

\section{Introduction}

Air temperature has increased during the last decades at a planetary scale, and it is expected to continue rising to at least the end of the present century, with the potential to increase atmospheric water vapour pressure deficit and, hence, water stress for plants (IPCC 2013). This is especially relevant in areas of the globe where warming is associated with reduction in rainfall, inducing the phenomenon known as "hotter drought", i.e. a simultaneous occurrence of rainfall reduction with an increase in air temperature (Allen et al. 2015). Hotter droughts are expected to increase in frequency and intensity, especially in dry and temperate ecosystems. In particular, Mediterranean-type ecosystems are among the areas where hotter droughts will increase thorough the current century (Giorgi and Lionello 2008). This phenomenon can potentially alter forest structure and functioning (Coomes et al. 2014) due to episodes of tree mortality (Allen et al. 2010; Plaut et al. 2013), lack of regeneration (Castro et al. 2004; Mendoza et al. 2009a; Matías et al. 2012a), reduction in biodiversity (Matías et al. 2011a; Mendoza et al. 2009b) or changes in species distribution (Jump and Peñuelas 2005; Matías and Jump 2015). The interactive effect of warming and drought has shown different results depending on the intensity and the affected species (Bauweraerts et al. 2013; Carón et al. 2015; Taeger et al. 2015). Accordingly, forecasting the impact of the combined effect of warmer and drier conditions on different tree species is of paramount importance to predict forest dynamics and its consequences on the ecosystem services they provide (Ibáñez et al. 2007; Morin and Thuiller 2009).

Most studies analysing the effects of hotter drought are focused on adult trees (McDowell et al. 2008; Allen et al. 2010), and there is comparatively less information about its effects on the juvenile stages. As a consequence of their limited root system and reserve content, growth and survival of juveniles are generally more sensitive to environmental conditions than adults (Lloret et al. 2009; but see Floyd et al. 2009 or Herrero and Zamora 2014 for contrasting results). Thus, recruitment is considered as the most important bottleneck in plant population dynamics and species distribution (Lloret et al. 2004). Summer drought limits regeneration in Mediterranean forests (Castro et al. 2004, 2005; Herrero et al. 2013; Moser et al. 2015). In this context, the hotter droughts expected for many regions worldwide will likely impose further limitations to the regeneration and persistence of many forest systems. Although the study of the response of adults to hotter drought is undoubtedly relevant, knowledge on the response at the seedling stage is absolutely necessary for improving predictions on forest dynamics since juvenile recruitment dynamics determines the potential for future replacement of adults (Hampe and Arroyo 2002; Castro et al. 2005).

Resistance to high temperature and drought strongly differs among plant species (Engelbrecht and Kursar 2003; Matías et al. 2012b), being correlated to transpiration and hydraulic adaptations (Irvine et al. 1998; Martínez-Vilalta et al. 2009), water use efficiency (Warren et al. 2001) or carbon and biomass allocation patterns (Galiano et al. 2011; Matías et al. 2012b, 2014; Villar-Salvador et al. 2015). During the last decades, significant effort has been devoted to determine the differences in drought resistance among provenances or families within many tree species (Cregg and Zhang 2001; Richter et al. 2012). In contrast, paradoxically, few studies have addressed the comparative ecophysiology of closely related tree species (Awada et al. 2003; Climent et al. 2011; Herrero et al. 2013), which is key for evidencing an ecophysiological basis of species distribution (but see Baltzer et al. 2008). Drought usually reduces plant performance, both in adults and saplings (Eilmann and Rigling 2012; Matías et al. 2014). However, temperature increase could enhance plant growth and survival as long as water availability does not limit plant performance. For example, survival of Pinus uncinata, which is distributed in high-elevation humid areas, increased with higher temperature (Ruiz-Benito et al. 2013). The effect of temperature increase on plant performance is largely determined by habitat and species characteristics (Awada et al. 2003). However, 
species that are closely related or with overlapping distribution areas may have distinct responses to environmental alterations (Lahti et al. 2005). Differences in drought and temperature response among cooccurring species could have profound consequences for inter- and intraspecific competitions, community composition and forest dynamics (Ruiz-Benito et al. 2013).

In this study, we sought to determine the effect of simulated future climatic conditions on the performance of five pine species that are widely distributed in Europe: Pinus halepensis, $P$. pinaster, $P$. nigra, $P$. sylvestris and $P$. uncinata. These species comprise $35 \%$ of the forest area in Europe (Köble and Seufert 2001) and differ in their resistance to reduced water availability and low temperature (Climent et al. 2009; Herrero et al. 2013). Climate models predict that the Mediterranean Region, where these species inhabit, is among the most vulnerable regions to climate change (Sheffield and Wood 2008). Thus, pine species that inhabit in the Mediterranean basin are an excellent study system to ascertain the effect of the forecasted changes in climate on seedling performance and to determine the physiological mechanisms underlying the differences in drought resistance across species.

Specifically, distribution models predict that pine species inhabiting cool and low-water stress locations, which are restricted to high mountains in the Mediterranean Region, will reduce their regional frequency more than the lowland Mediterranean species in response to the forecasted increase in aridity (García-Valdés et al. 2013, 2015). However, these models usually provide information about future changes in species distributions at broad spatial scales and are based on adult trees, and they do not provide explication about the mechanisms involved in those changes or the consequences for seedling recruitment. Here, we conducted a controlled conditions experiment to compare the performance of seedlings grown under simulated current climatic conditions relative to seedlings grown under forecasted future climatic scenarios. These scenarios consist of a reduction in rainfall with respect to current conditions, an increase in temperature, or both, creating therefore four potential scenarios that simulate future climatic conditions according to predictive models. We hypothesise that pine species that inhabit dry, low-elevation sites will perform better under an increase in temperature and a reduction in water availability than pine species inhabiting cold and wet locations. Specifically, we ask the following questions: (1) Do survival and growth of ecologically distinct pine species respond differently to the predicted increases in temperature and drought? (2) Are the effects of increased temperature and reduced rainfall independent, additive or antagonistic? (3) Are there differences among species in physiological and morphological traits related to drought stress tolerance in response to hotter drought? By answering these questions, we aim to improve our understanding of the capacity of pine species to tolerate predicted changes in conditions and resources at the seedling stage, and consequently better predict their population dynamics.

\section{Materials and methods}

Species and plant material

The five focal species used in this study belong to the genus Pinus. Two species ( $P$. halepensis and $P$. pinaster) are distributed in the Mediterranean basin and occupy mainly lowland dry locations. P. halepensis grows from sea level to $1500 \mathrm{~m}$ a.s.l., while $P$. pinaster grows up to $1800 \mathrm{~m}$ a.s.l. The rest of the species ( $P$. nigra, $P$. sylvestris and $P$. uncinata) inhabit colder and wetter locations than $P$. halepensis and $P$. pinaster, and are restricted to high mountain areas in the Mediterranean basin. Seeds from the five species were collected from certified provenance regions of the Iberian Peninsula (Appendix S1) and stored in cold, dry conditions until sowing. Seeds were germinated in a glasshouse at the University of Stirling (UK) by placing them into $3 \times 3 \times 5 \mathrm{~cm}$ sowing pots filled with peat. To assure a synchronisation of seedling emergence across species, sowing started with $P$. halepensis on 29th April 2013. Pinus pinaster was sown 6 days later; $P$. nigra and $P$. uncinata were sown 15 days after $P$. halepensis, and finally $P$. sylvestris was sown 20 days after $P$. halepensis sowing (VillarSalvador personal communication). Seedlings were grown in the glasshouse until 17th June, following which they were transplanted to $8 \mathrm{~cm}$ in diameter and $45 \mathrm{~cm}$ high tubular PVC pots filled with a peat and river sand mixture (proportion 2:1 in volume, respectively) with a layer of gravel at the bottom to facilitate drainage. 
Experimental set up

We performed the experiment under controlled environmental conditions in which we simulated different climatic scenarios. As a reference climate, we selected the average summer conditions in a location from a Mediterranean mountain where four of the five studied species ( $P$. halepensis, $P$. pinaster, $P$. nigra and $P$. sylvestris) naturally co-occur within a 1500-1800 m a.s.l. altitudinal band (Sierra Nevada National Park, SE Spain; $37^{\circ} 05^{\prime} 06^{\prime \prime} \mathrm{N}, 03^{\circ} 28^{\prime} 12^{\prime \prime} \mathrm{W}$; see Matías et al. 2014 for a similar procedure). Annual precipitation in this area is $828 \mathrm{~mm}$ (mean 1990-2012; meteorological station placed at $1670 \mathrm{~m}$ a.s.1 in La Cortijuela Botanical Garden). Mean annual temperature, mean maximum temperature of the hottest month and mean minimum temperature of the coldest month are 11.0, 29.2 , and $-1.3{ }^{\circ} \mathrm{C}$, respectively. These conditions represent the lower altitudinal limits for $P$. sylvestris, $P$. nigra and $P$. uncinata, and the upper altitudinal edge for $P$. halepensis and $P$. pinaster. A mesocosm experiment controlling environmental conditions was conducted using Snijders Scientific (Tilburg, Netherlands) MC1750E controlled environment chambers at the University of Stirling (UK). Pots with seedlings grown at the glasshouse were placed into four chambers (inner space $1.8 \mathrm{~m}$ length $\times 0.75 \mathrm{~m}$ wide $\times 1.2 \mathrm{~m} \mathrm{high}$ ) that simulated two temperature scenarios (current and future temperatures, CT and FT, respectively; two replicate chambers per temperature scenario). CT scenario represented the mean monthly day and night temperatures at the reference site during the growing season for the 1990-2010 temperature series $\left(25 / 10{ }^{\circ} \mathrm{C}\right.$ in June for day and night temperature, respectively; $29 / 14{ }^{\circ} \mathrm{C}$ for July and August and $22 / 10{ }^{\circ} \mathrm{C}$ for September). FT scenario simulated the predicted $4{ }^{\circ} \mathrm{C}$ increase in day and night temperature respect to $\mathrm{CT}$ values for the end of the present century in the reference area (A2 scenario; IPCC 2013). The simulated temperature increase lies within the range of summer temperatures for large areas of Southern Europe where several focal species are present, and furthermore lies within the expected temperatures for large areas of southern and central Europe for the second half of the current century (Giorgi and Lionello 2008; IPCC 2013). Within each chamber, we simulated two precipitation patterns (current and future precipitation, CP and FP, respectively). CP scenario was based on the mean precipitation records at the reference site during the growing season (June-September, $118 \mathrm{~mm}$; Matías et al. 2011b). FP scenario simulated the predicted reduction in precipitation by $30 \%$ for the end of the century $(82.6 \mathrm{~mm})$. These precipitation amounts were distributed along 12 weekly irrigation events. From the 12nd experimental week (9th September 2013), irrigation was stopped for 6 weeks to simulate Mediterranean summer drought (Quero et al. 2011). Thus, in our experimental design, temperature was a whole plot factor, fully crossed with precipitation and species as subplot factors. Each chamber contained 11 seedlings of each species per irrigation level, making a total of 22 seedlings per species and treatment combination (440 seedlings in total).

Photosynthetic photon flux density of $210 \mu \mathrm{mol} \mathrm{m} \mathrm{s}^{2}$ was applied constantly for $14 \mathrm{~h}$, with one additional hour of progressive intensity rise at dawn and $1 \mathrm{~h}$ of progressive decrease at dusk. This is a representative value for forest understory in summer (Valladares et al. 2004). Air relative humidity and $\mathrm{CO}_{2}$ concentration were kept constant within cabinets at $65 \%$ and $450 \mathrm{ppm}$, respectively. In order to not limit nutrient availability, $0.5 \mathrm{~g}$ of a slow-release NPK fertiliser (Osmocote ${ }^{\circledR}$ Controlled Release) was added to each pot, which is equivalent to $140 \mathrm{~g} \mathrm{~m}^{-2}$ as recommended by the supplier. To avoid any possible chamber effect, all pots were periodically rotated through chambers, each pot remaining at least 1 month in each chamber, while also randomising pot position within chambers. Soil moisture was measured fortnightly during the experiment on top soil in all pots using the time-domain reflectometry method with $5 \mathrm{~cm}$ in length rods (SM300; Delta-T devices, Cambridge, UK). Soil moisture was recorded $48 \mathrm{~h}$ after an irrigation event on the half of the experimental pots $(N=11$ per species and treatment combination). On 21st October (18 weeks after the onset of the experiment), all surviving seedlings were harvested. Roots were carefully washed to remove the substratum remains. The maximum root length was measured, and then seedlings were divided into shoots and roots, oven-dried at $60{ }^{\circ} \mathrm{C}$ for $72 \mathrm{~h}$ and weighed.

\section{Seedling measurements}

Survival was monitored weekly during the period of the experiment. Final growth was measured in all surviving seedlings at the end of the experiment 
considering the variables' maximum root length, shoot length, root biomass, shoot biomass and total plant biomass. The maximum photochemical efficiency of photosystem II $\left(F_{\mathrm{v}} / F_{\mathrm{m}}\right)$ and the plant water potential $(\Psi)$ were measured in all surviving seedlings before the final harvest. $F_{\mathrm{v}} / F_{\mathrm{m}}$ was measured with a portable fluorometer (FMS2, Hansatech Instruments, UK) at predawn just before the final harvest. $\Psi$ of all plants was measured around midday with a pressure chamber (Manofrigido, Lisbon, Portugal) using the leader shoot. Also, we calculated the hotter drought resistance of each species $\left(D_{\mathrm{B}}\right)$ as the biomass in the future scenario relative to the current scenario biomass:

$D_{\mathrm{B}}=\left(\frac{B_{\mathrm{F}}}{B_{\mathrm{C}}}\right) \times 100$,

where $B_{\mathrm{F}}$ and $B_{\mathrm{C}}$ are the final biomass of seedlings under future temperature and precipitation (FT + FP treatments) and current temperature and precipitation $(\mathrm{CT}+\mathrm{CP}$ treatment) scenarios, respectively (based on Engelbrecht and Kursar 2003).

Data analysis

Variation in soil moisture among treatments was tested by repeated measures ANOVA. Seedling survival was analysed by a Generalised Linear Model, with a binomial error distribution and logit link function, including the three experimental factors (temperature, precipitation and species) and their fullfactorial interactions. Differences in total biomass, root length, root-to-shoot ratio and $F_{\mathrm{v}} / F_{\mathrm{m}}$ across the different factors were tested by ANOVA tests. Since size of the plant may influence its water status (Cuesta et al. 2010), total biomass was included as a covariate in the analysis of treatment effects on $\Psi$. All variables were transformed (log, square root) to meet normality assumptions when necessary. Results are given as mean $\pm \mathrm{SE}$ throughout the paper.

\section{Results}

Soil moisture

Soil moisture was affected by all main factors, being higher in the $\mathrm{CP}$ than in the FP treatment (mean values for the experiment duration $11.2 \pm 0.2$ and $7.3 \pm 0.2 \%$, respectively; $F=164.4, \quad P<0.001$; Appendix S2), and under CT than under FT $(9.7 \pm 0.2$ and $8.7 \pm 0.2 \%$, respectively; $F=20.0$, $P<0.001)$. Besides receiving the same amount of water, soil moisture differed among species ( $F=13.2, P<0.001)$, decreasing from $P$. nigra (mean value across treatments $10.7 \pm 0.3 \%$ ) to $P$. uncinata $(10.5 \pm 0.4 \%)$, P. sylvestris $(9.4 \pm 0.3 \%)$, $P$. halepensis $(8.8 \pm 0.3 \%)$ and $P$. pinaster $(7.3 \pm 0.3 \%)$. This trend resulted from a negative correlation between seedling mass and soil moisture across species $(r=0.14 ; P=0.04)$, probably indicating a biotic effect on soil moisture through plant transpiration. No significant interactions were found among any of these factors (data not shown).

Seedling survival, growth and biomass allocation pattern

Seedling survival was high overall, with values over 94\% across species, but differed across experimental treatments (Table 1). Under current climate (CT + CP scenario), survival was $100 \%$ for all species, but the combination of FT and FP scenarios reduced it for almost all species: $P$. uncinata survival reduced to $81.8 \%, P$. nigra to $90.9 \%, P$. sylvestris and $P$. pinaster to $95.5 \%$, and $P$. halepensis was not affected. Seedling biomass differed among the four experimental treatments (Table 1). Overall, biomass differences among species followed the order $P$. pinaster $>P$. halepensis $=P$. nigra $>P$. sylvestris $>P$. uncinata $(>$ symbol denotes significant differences after Bonferroni post hoc tests, hereafter). Among climatic scenarios, seedling biomass decreased from current conditions to the most extreme future conditions (FT + FP; Fig. 1). However, the pattern changed slightly across species, which resulted in a significant species $\times$ precipitation interaction and a marginally significant species $\times$ temperature interaction (Table 1; Fig. 1). Nonetheless, a common, overall pattern was the consistent significant difference in biomass between the current climate conditions and the hotter drought climate scenario (FT + FP; Fig. 1). Similarly, a general pattern was a similar effect within species provoked by warming (FT scenario) or drought increase (FP scenario) alone (Fig. 1). Thus, although warming and drought had a 
Table 1 Results of the GLM test for survival ( $\chi^{2}$ values with $P$ values within brackets) and ANOVA tests for all other variables ( $F$ values with $P$ values within brackets) for the effect

\begin{tabular}{|c|c|c|c|c|c|c|c|}
\hline & Survival & Biomass & Root-to-Shoot & Root length & $\Psi$ & $F_{\mathrm{v}} / F_{\mathrm{m}}$ & $d f$ \\
\hline Species & $9.1(\mathbf{0 . 0 5})$ & $135(<\mathbf{0 . 0 0 1})$ & $67(<\mathbf{0 . 0 0 1})$ & $120(<\mathbf{0 . 0 0 1})$ & $21.8(<\mathbf{0 . 0 0 1})$ & $2.6(\mathbf{0 . 0 4})$ & 4 \\
\hline Temperature & $3.9(\mathbf{0 . 0 4})$ & $176(<\mathbf{0 . 0 0 1})$ & $38(<\mathbf{0 . 0 0 1})$ & 9.1 (0.003) & $23.3(<\mathbf{0 . 0 0 1})$ & $3.5(\mathbf{0 . 0 6})$ & 1 \\
\hline Precipitation & 7.7 (0.005) & $199(<\mathbf{0 . 0 0 1})$ & $0.0(0.98)$ & $28(<\mathbf{0 . 0 0 1})$ & $156.6(<\mathbf{0 . 0 0 1})$ & $0.3(0.59)$ & 1 \\
\hline $\mathrm{S} \times \mathrm{T}$ & $1.2(0.88)$ & $2.3(0.06)$ & $1.0(0.42)$ & $1.9(0.11)$ & $0.6(0.63)$ & $2.4(\mathbf{0 . 0 5})$ & 4 \\
\hline $\mathrm{S} \times \mathrm{P}$ & $2.8(0.42)$ & 4.4 (0.002) & $1.8(0.12)$ & $1.2(0.31)$ & $2.4(\mathbf{0 . 0 5})$ & $1.4(0.25)$ & 4 \\
\hline $\mathrm{T} \times \mathrm{P}$ & $0.0(1.0)$ & $0.1(0.87)$ & $0.1(0.78)$ & $0.1(0.80)$ & $1.5(0.22)$ & $0.1(0.77)$ & 1 \\
\hline $\mathrm{S} \times \mathrm{T} \times \mathrm{P}$ & & $1.3(0.29)$ & $1.4(0.22)$ & $0.2(0.96)$ & $0.4(0.80)$ & $0.5(0.74)$ & 4 \\
\hline Biomass & & & & & $47.8(<\mathbf{0 . 0 0 1})$ & & 1 \\
\hline
\end{tabular}

Significant variables are indicated in bold

Total plant biomass was included as a covariable for water potential $(\Psi)$

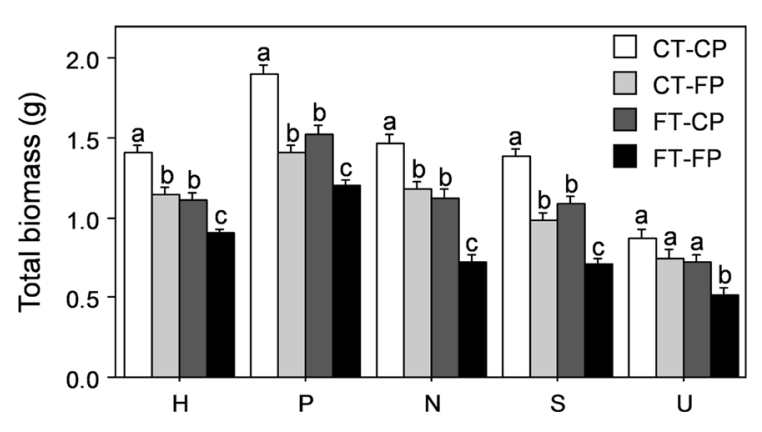

Fig. 1 Total biomass at the end of the experiment for the different species (H: P. halepensis; $\mathrm{P}:$ P. pinaster; N: P. nigra; $\mathrm{S}$ : $P$. sylvestris; and $\mathrm{U}: P$. uncinata) growing under the different temperatures ( $C T$ current temperature, $F T$ future temperature) and precipitation $(C P$ current precipitation, $F P$ future precipitation) scenarios. Different letters denote differences between scenarios within the same species after Bonferroni post hoc test. Error bars represent $\pm \mathrm{SE}$

negative impact on seedling biomass, their effects were additive when both factors were combined.

Root length also differed among species, temperature and precipitation treatments, and followed a similar trend as that of biomass, with no significant interactions among factors. Thus, Mediterranean pines showed longer roots than mountain pines (Appendix S3). Biomass allocation pattern (root-to-shoot ratio) differed among species (Table 1), following the order $P$. uncinata $>P$. sylvestris $>P$. halepensis $\geq P$. nigra $=P$. pinaster (Fig. 2). Temperature reduced root-to-shoot ratio similarly (Table 1) in all the species (Fig. 2) by $13.5 \%$ (mean value across species). These changes in biomass in response to the simulated of the three main factors (species, temperature and precipitation) on the different response variables 


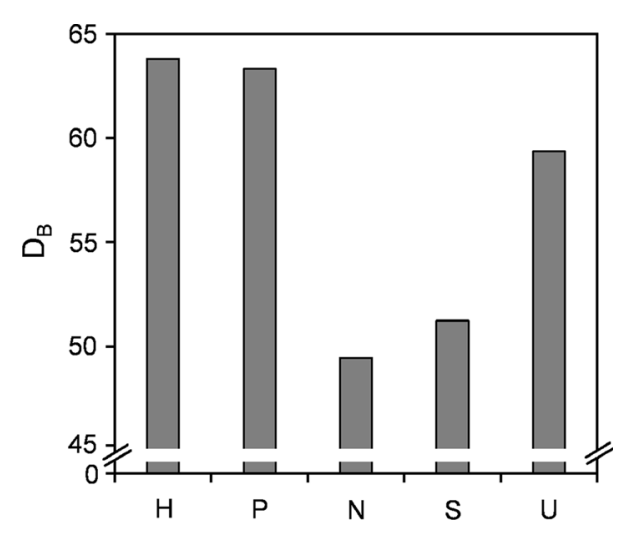

Fig. 3 Drought resistance index in terms of biomass $\left(D_{\mathrm{B}}\right)$ calculated as biomass produced by the different species under future climatic conditions (FT + FP) with respect to current climatic conditions $(\mathrm{CT}+\mathrm{CP})$, ranging from 0 (strongest effect) to 100 (no effect)

(more negative values) that was consistent for all the species (no significant interactions; Table 1c; Fig. 4). In addition, warming slightly decreased $\Psi$ under the warmer scenario (CT: $-1.60 \pm 0.04 \mathrm{MPa}$; FT: $-1.67 \pm 0.05 \mathrm{MPa}) . F_{\mathrm{v}} / F_{\mathrm{m}}$ was little affected by treatments, although there were differences among species (Table 1; Fig. 5). There was also a species $\times$ temperature interaction as a consequence of a greater reduction in $F_{\mathrm{v}} / F_{\mathrm{m}}$ under increased temperature (FT treatment) for $P$. pinaster and $P$. sylvestris, but not for the rest of the species (Fig. 5). Across treatments, $F_{\mathrm{v}} / F_{\mathrm{m}}$ varied among species

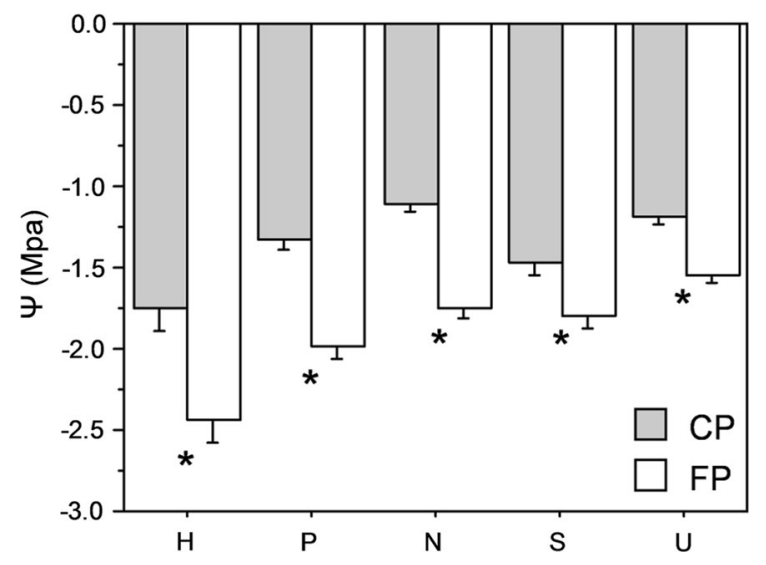

Fig. 4 Plant water potential ( $\Psi$, in $\mathrm{MPa}$ ) under the different precipitation treatments (current, $\mathrm{CP}$; future, $\mathrm{FP}$ ) for the different pine species (H: P. halepensis; $\mathrm{P}: P$. pinaster; N: $P$. nigra; S: P. sylvestris; and U: P. uncinata). Asterisks denote significant differences between temperature levels. Error bars represent $\pm \mathrm{SE}$

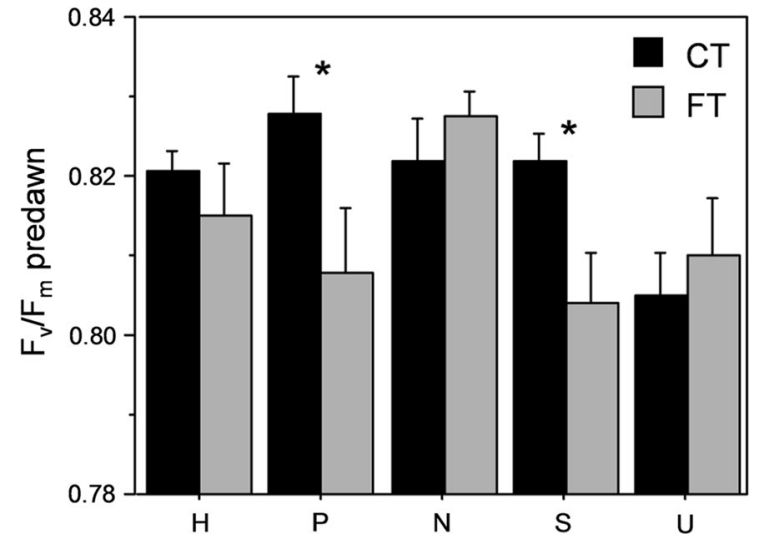

Fig. 5 Leaf fluorescence $\left(F_{\mathrm{v}} / F_{\mathrm{m}}\right)$ at predawn under the different temperature scenarios (current, CT; future, FT) for the different pine species (H: P. halepensis; $\mathrm{P}: P$. pinaster; N: $P$. nigra; S: P. sylvestris; and U: P. uncinata). Asterisks denote significant differences between temperature levels. Error bars represent $\pm \mathrm{SE}$

following the order $P$. nigra $>$ P. halepensis $=P$. pinaster $=P$. sylvestris $>$ P. uncinata.

\section{Discussion}

This study provides experimental evidence of the differential effect of hotter drought on seedling performance of five major pine species that inhabit in the Mediterranean basin. The forecast increase in summer temperature and drought reduced seedling survival, growth and biomass root allocation across species, increased water stress and reduced the maximum photochemical efficiency. Overall, either an increase of temperature or drought alone reduced seedling performance, but the highest impact occurred when these two factors acted concomitantly. However, species did not respond in the same manner, with typical lowland Mediterranean pines ( $P$. halepensis and $P$. pinaster) showing higher stress tolerance than mountain pines in terms of highest growth in the most stressful scenario relative to the less stressful environment.

Consequences of forecasted climate alterations on seedling performance

Our results showed little effect of the treatments on survival, which was above $80 \%$ for all the species. This high survival is likely to be a consequence of the 
experimental conditions, where the higher air relative humidity, $\mathrm{CO}_{2}$ concentration and lower radiation intensity with respect to conditions in the wild may have reduced water stress (Polley et al. 1996; Kolb and Robberecht 1996; Bauweraerts et al. 2013). Nonetheless, we could still detect a clear pattern in survival, being lowest for high mountain species and highest for both Mediterranean species that inhabit drier areas $(P$. halepensis and $P$. pinaster), a fact that is consistent with the different responses of these species reported by others to the increase in aridity (Sánchez-Salguero et al. 2012; Herrero et al. 2013; Ruiz-Benito et al. 2013; Camarero et al. 2015).

Simulated warming and drought, by contrast, clearly reduced growth across species. In droughtprone areas such as the Mediterranean Region, drought increases evapotranspiration, which can intensify plant water stress and reduce growth (Sánchez-Salguero et al. 2012; Herrero et al. 2013). Reduction in growth in response to increased temperature can also be attributed to a higher respiration rate (Way and Oren 2010). Consequently, both temperature rise and drought intensification are affecting seedling performance in the same direction by reducing biomass gain during the first summer. In addition, their combined effect was much larger than both factors separately, inducing an additive negative impact under a hotter drought scenario.

Higher growth during the first growing season can increase inter- and intraspecific competition capacity and survival to the first summer drought in Mediterranean environments (Castro 2006; Villar-Salvador et al. 2012), with smaller seedlings growing under a hotter drought scenario likely having lower establishment probability. Interestingly, species growth did not respond with the same intensity to the hotter drought. In accordance with the $D_{\mathrm{B}}$ index, which measures hotter drought resistance in terms of biomass (hence an integrative parameter normalised by species-specific plant size; Fig. 3), the two Mediterranean pines ( $P$. halepensis and $P$. pinaster) are the most droughttolerant species, whereas $P$. sylvestris and $P$. nigra are the most susceptible to our simulated hotter drought. Moreover, Mediterranean pines had longer roots than Mountain pines.

Warming also reduced the proportion of biomass allocated to roots (lower root-to-shoot ratio) and root length across species. This decrease in the proportion of biomass allocated to roots and low root development might reduce drought resistance and survival (Collins and Bras 2007; Matías et al. 2014) as they increase imbalance in water economy (Grossnickle 2012) and decrease the exploration of deep soil layers for water uptake, respectively (Padilla and Pugnaire 2007; Paula and Ojeda 2009). Surprisingly, the high mountain pine, $P$. uncinata, presented a $D_{\mathrm{B}}$ value rather higher than that of $P$. nigra and $P$. sylvestris (Fig. 5). This difference of $P$. uncinata from the other mountain pines can likely be explained by the higher biomass allocation to roots, presenting the highest R:S of the five studied species. As discussed previously, R:S is a key trait for the maintenance of water balance under drought stress, which can also limit performance of perennial plants in very cold climates due to low soil temperature (Körner and Larcher 1988), and points to adaptation of $P$. uncinata to harsh and moist montane environments. However, although $P$. uncinata presented high resistance to hotter drought in terms of biomass reduction, it was the species with the lowest survival and growth that had the highest photoinhibition, indicating that it is likely very sensitive to the increase in aridity. In this sense, $P$. uncinata showed the lowest $F_{\mathrm{v}} / F_{\mathrm{m}}$ values under current temperature conditions, indicating that this pine suffers photoinhibition even under present climatic conditions. This suggests that $P$. uncinata is the least adapted of the pines investigated here to the dry and hot summer conditions typical of the Mediterranean climate, which is consistent with its high mountain distribution and the fact that seedlings had the lowest survival and growth in our experiment. Our results also suggest that increase in aridity will have little impact on photoinhibition of pine species, as $F_{\mathrm{v}} /$ $F_{\mathrm{m}}$ values were overall high under hotter drought. Only $P$. pinaster and $P$. sylvestris showed clear reductions in $F_{\mathrm{v}} / F_{\mathrm{m}}$ in response to temperature increase. The low-light conditions in our experiments might have prevented detecting larger differences among treatments and species.

Pinus species have been considered as isohydric when compared to either oaks or junipers (Zweifel et al. 2007; Meinzer et al. 2014). However, based on the observed minimum water potentials, the studied pines can be ordered along an iso-anisohydric axis from $P$. uncinata, $P$. sylvestris, $P$. nigra, $P$. pinaster to $P$. halepensis. Isohydric species close stomata when confronted with dry soil conditions, limiting transpiration, and thus avoiding hydraulic failure by xylem 
embolism. Anisohydric species keep stomata open for longer periods of time, maintaining relatively high transpiration rates during the drought period. Contrary to isohydric plants, the more negative water potential might cause hydraulic failure by xylem embolism (Tyree and Zimmermann 2002). Surprisingly, the most anisohydric species in our study, i.e. P. halepensis and $P$. pinaster, are also the most drought-tolerant species as discussed above, which seems plausible given that these species can keep higher carbon assimilation during summer drought (Voltas et al. 2015). However, this potential advantage under dry current conditions can turn into disadvantage under the forecast drier conditions, where more negative water potentials may increase the risk of xylem embolism and thus tree mortality. Indeed, species distribution models considering similar future climate scenarios than those considered in this study resulted into range displacements of $P$. halepensis to more mesic areas (Ruiz-Benito et al. 2012). These processes can be even observed currently in $P$. halepensis plantations in semiarid areas of the eastern Iberian Peninsula, where massive tree mortality is already occurring (Camarero et al. 2015).

Implications for the future distribution of pine species

The five species are distributed across an altitudinal gradient in the Mediterranean basin, replacing each other depending on their stress tolerance (Richardson and Bond 1991). Thus, the expected changes in climate have the potential to alter current species' distributions (Greenwood et al. 2015; Leverkus et al. 2015). This change in distribution might be a consequence of alterations in recruitment by means of decreased growth, lower biomass investment to roots and, in some cases, photoinhibition. Based on the results presented here, $P$. halepensis and $P$. pinaster are the species whose seedlings have higher drought resistance to warming and lowest water potential (especially $P$. halepensis). If the frost limitation at high elevations becomes less frequent and intense in the coming decades (Giorgi and Lionello 2008), we could expect these species to progressively colonise zones at higher altitude. However, the maintenance of lowland populations will depend on their capacity to resist extreme climatic events such as heatwaves or extreme drought events, which are responsible for massive mortality events (Bigler et al. 2006; Herrero et al. 2013). This is especially relevant for $P$. pinaster, as the photoinhibition here detected in response to warming might reduce its potential to colonise new areas and could imperil its persistence at lowland if heatwaves are more frequent. Pinus nigra and $P$. sylvestris are the most vulnerable species to warming and drought. This higher vulnerability implies a low tolerance to climate alterations, and therefore we could expect a range displacement for these species to higher elevations and the decline of populations at lower altitude, especially when warming and reduced precipitation act concomitantly. This result agrees with the already described displacement pattern for natural $P$. sylvestris populations (Matías and Jump 2015). Finally, P. uncinata is a special case since, although it had an intermediate drought resistance in terms of biomass reduction, it also presented the lowest survival, biomass and root length. Hence, it is also expected to reduce its distribution in Southern Europe under a scenario of generalised hotter drought. However, beside these general trends in response to climate, we also have to take into account the biotic interactions in the prediction of range shifts, such as herbivory, competition with other species (especially Quercus spp.) or parasitic interactions, which could drastically alter the above-described pattern (see Matías and Jump 2012 for a review).

Acknowledgements We thank P. González-Díaz for her inestimable help during the experiment development. This work was supported by the project ECOLPIN (AGL201124296) to P.V-S. and by EU Marie Curie (FP7-2011-IEF300825) and Juan de la Cierva (FPDI-2013-15867) Fellowships to L.M.

Open Access This article is distributed under the terms of the Creative Commons Attribution 4.0 International License (http:// creativecommons.org/licenses/by/4.0/), which permits unrestricted use, distribution, and reproduction in any medium, provided you give appropriate credit to the original author(s) and the source, provide a link to the Creative Commons license, and indicate if changes were made.

\section{References}

Allen CD, Macalady AK, Chenchouni H, Bachelet D, McDowell N, Vennetier M, Kitzberger T, Rigling A, Breshears DD, Hogg EH, Gonzalez P, Fensham R, Zhang Z, Castro J, Demidova N, Lim JH, Allard G, Running SW, 
Semerci A, Cobb N (2010) A global overview of drought and heat-induced tree mortality reveals emerging climate change risks for forests. For Ecol Manage 259:660-684

Allen CD, Breshears DD, McDowell NG (2015) On underestimation of global vulnerability to tree mortality and forest die-off from hotter drought in the Anthropocene. Ecosphere 6:art129

Awada T, Radoglou K, Fotelli MN, Constantinidou HIA (2003) Ecophysiology of seedlings of three Mediterranean pine species in contrasting light regimes. Tree Physiol 23:33-41

Baltzer JL, Davies SJ, Bunyavejchewin S, Noor NSM (2008) The role of desiccation tolerance in determining tree species distributions along the Malay-Thai Peninsula. Funct Ecol 22:221-231

Bauweraerts I, Wertin TM, Ameye M, McGuire MA, Teskey RO, Steppe K (2013) The effect of heat waves, elevated $\left[\mathrm{CO}_{2}\right]$ and low soil water availability on northern red oak (Quercus rubra L.) seedlings. Glob Chang Biol 19:517-528

Bigler C, Bräker OU, Bugmann H, Dobbertin M, Rigling A (2006) Drought as an inciting mortality factor in Scots pine stands of the Valais, Switzerland. Ecosystems 9:330-343

Camarero JJ, Gazol A, Sangüesa-Barreda G, Oliva J, VicenteSerrano SM (2015) To die or not to die: early warnings of tree dieback in response to a severe drought. J Ecol 103:44-57

Carón MM, De Frenne P, Brunet J, Chabrerie O, Cousins SAO, De Backer L, Decocq G, Diekmann M, Heinken T, Kilb A, Naaf T, Plue J, Selvi F, Strimbeck GR, Wulf M, Verheyen $\mathrm{K}$ (2015) Interacting effects of warming and drought on regeneration and early growth of Acer pseudoplatanus and A. platanoides. Plant Biol 17:52-62

Castro J (2006) Short delay in timing of emergence determines establishment success in Pinus sylvestris across microhabitats. Ann Bot 98:1233-1240

Castro J, Zamora R, Hódar JA, Gómez JM (2004) Seedling establishment of a boreal tree species (Pinus sylvestris) at its southernmost distribution limit: consequences of being in a marginal Mediterranean habitat. J Ecol 92:266-277

Castro J, Zamora R, Hódar JA, Gómez JM (2005) Alleviation of summer drought boosts establishment success of Pinus sylvestris in a Mediterranean mountain: an experimental approach. Plant Ecol 181:191-202

Climent J, Costa e Silva F, Chambel MR, Pardos M, Almeida MH (2009) Freezing injury in primary and secondary needles of Mediterranean pine species of contrasting ecological niches. Ann For Sci 66:407-407

Climent J, Chambel MR, Pardos M, Lario F, Villar-Salvador P (2011) Biomass allocation and foliage heteroblasty in hard pine species respond differentially to reduction in rooting volume. Eur J For Res 130:841-850

Collins DBG, Bras RL (2007) Plant rooting strategies in waterlimited ecosystems. Water Resour Res 43, article W06407

Coomes DA, Flores O, Holdaway R, Jucker T, Lines ER, Vanderwel MC (2014) Wood production response to climate change will depend critically on forest composition and structure. Glob Chang Biol 20:3632-3645

Cregg BM, Zhang JW (2001) Physiology and morphology of Pinus sylvestris seedlings from diverse sources under cyclic drought stress. For Ecol Manage 154:131-139
Cuesta B, Vega J, Villar-Salvador P, Rey-Benayas JM (2010) Root growth dynamics of Aleppo pine (Pinus halepensis Mill.) seedlings in relation to shoot elongation, plant size and tissue nitrogen concentration. Trees 24:899-908

Eilmann B, Rigling A (2012) Tree-growth analyses to estimate tree species' drought tolerance. Tree Physiol 32:178-187

Engelbrecht BMJ, Kursar TA (2003) Comparative drought-resistance of seedlings of 28 species co-occurring tropical woody plants. Oecologia 136:383-393

Floyd ML, Clifford M, Cobb NS, Hanna D, Delph R, Ford P, Turner D (2009) Relationship of stand characteristics to drought-induced mortality in three southwestern piñonjuniper woodlands. Ecol Appl 19:1223-1230

Galiano L, Martínez-Vilalta J, Lloret F (2011) Carbon reserves and canopy defoliation determine the recovery of scots pine 4 yr after a drought episode. New Phytol 190:750-759

García-Valdés R, Zavala MA, Araujo MB, Purves DW (2013) Chasing a moving target: projecting climate change-induced shifts in non-equilibrial tree species distributions. J Ecol 101:441-453

García-Valdés R, Svenning J-C, Zavala MA, Purves DW, Araújo MB (2015) Evaluating the combined effects of climate and land-use change on tree species distributions. J Appl Ecol 52:902-912

Giorgi F, Lionello P (2008) Climate change projections for the Mediterranean region. Glob Planet Change 63:90-104

Greenwood S, Chen J-C, Chen C-T, Jump AS (2015) Temperature and sheltering determine patterns of seedling establishment in an advancing subtropical treeline. J Veg Sci 26:711-721

Grossnickle SC (2012) Why seedlings survive: influence of plant attributes. New For 43:711-738

Hampe A, Arroyo J (2002) Recruitment and regeneration in populations of an endangered South Iberian Tertiary relict tree. Biol Conserv 107:263-271

Herrero A, Zamora R (2014) Plant responses to extreme climatic events: a field test of resilience capacity at the southern range edge. PLoS ONE. doi:10.1371/journal.pone. 0087842

Herrero A, Castro J, Zamora R, Delgado-Huertas A, Querejeta JI (2013) Growth and stable isotope signals associated with drought-related mortality in saplings of two coexisting pine species. Oecologia 173:1613-1624

Ibáñez I, Clark JS, LaDeau S, Hille Ris Lambers J (2007) Exploiting temporal variability to understand tree recruitment response to climate change. Ecol Monogr 77:163-177

IPCC (2013) Climate change 2013: the physical science basis. Contribution of working group I to the fifth assessment report of the intergovernmental panel on climate change

Irvine J, Perks MP, Magnani F, Grace J (1998) The response of Pinus sylvestris to drought: stomatal control of transpiration and hydraulic conductance. Tree Physiol 18:393-402

Jump AS, Peñuelas J (2005) Running to stand still: adaptation and the response of plants to rapid climate change. Ecol Lett 8:1010-1020

Köble R, Seufert G (2001) Novel maps for forest tree species in Europe. In: Proceedings of the 8th European symposium on the physico-chemical behaviour of air pollutants: a changing atmosphere! Torino (IT), 17-20 Sept 2001 
Kolb PF, Robberecht R (1996) High temperature and drought stress effects on survival of Pinus ponderosa seedlings. Tree Physiol 16:665-672

Körner C, Larcher W (1988) Plant life in cold climates. In: Long SF, Woodward FI (eds) Plants and temperature. Symposium of the society of experimental biology 42:25-57. The Company of Biol Ltd, Cambridge

Lahti M, Aphalo PJ, Finér L, Ryyppö A, Lehto T, Mannerkoski $\mathrm{H}$ (2005) Effects of soil temperature on shoot and root growth and nutrient uptake of 5-year-old Norway spruce seedlings. Tree Physiol 25:115-122

Leverkus AB, Castro J, Delgado-Capel MJ, Molinas-González C, Pulgar M, Marañón-Jiménez S, Delgado-Huertas A, Querejeta JI (2015) Restoring for the present or restoring for the future: enhanced performance of two sympatric oaks (Quercus ilex and Quercus pyrenaica) above the current forest limit. Rest Ecol. doi:10.1111/rec.12259

Lloret F, Peñuelas J, Estiarte M (2004) Experimental evidence of reduced diversity of seedlings due to climate modification in a Mediterranean-type community. Glob Chang Biol 10:248-258

Lloret F, Peñuelas J, Prieto P, Llorens L, Estiarte M (2009) Plant community changes induced by experimental climate change: seedling and adult species composition. Perspect Plant Ecol Evol Syst 11:53-63

Martínez-Vilalta J, Cochard H, Mencuccini M, Sterck F, Herrero A, Korhonen JFJ, Llorens P, Nikinmaa E, Nolè A, Poyatos R, Ripullone F, Sass-Klaassen U, Zweifel R (2009) Hydraulic adjustment of scots pine across Europe. New Phytol 184:353-364

Matías L, Jump AS (2012) Interactions between growth, demography and biotic interactions in determining species range limits in a warming world: the case of Pinus sylvestris. For Ecol Manage 282:10-22

Matías L, Jump AS (2015) Asymmetric changes of growth and reproductive investment herald altitudinal and latitudinal range shifts of two woody species. Glob Chang Biol 21:882-896

Matías L, Castro J, Zamora R (2011a) Soil nutrient availability under a global change scenario in a Mediterranean mountain ecosystem. Glob Chang Biol 17:1646-1657

Matías L, Zamora R, Castro J (2011b) Repercussions of simulated climate change on the diversity of woody-recruit bank in a Mediterranean-type ecosystem. Ecosystems 14:672-682

Matías L, Quero JL, Zamora R, Castro J (2012a) Evidence for plant traits driving specific drought resistance. A community field experiment. Environ Exp Bot 81:55-61

Matías L, Zamora R, Castro J (2012b) Rare rainy events are more critical than drought intensification for woody recruitment in Mediterranean mountains: a field experiment simulating climate change. Oecologia 169:833-844

Matías L, González-Díaz P, Jump AS (2014) Larger investment in roots in southern range-edge populations of Scots pine is associated with increased growth and seedling resistance to extreme drought in response to simulated climate change. Environ Exp Bot 105:32-38

McDowell N, Pockman WT, Allen CD, Breshears DD, Cobb N, Kolb T, Plaut J, Sperry J, West A, Williams DG, Yepez EA (2008) Mechanisms of plant survival and mortality during drought: why do some plants survive while others succumb to drought? New Phytol 178:719-739

Meinzer FC, Woodruff DR, Marias DE, McCulloh KA, Sevanto $S$ (2014) Dynamics of leaf water relations components in co-occurring iso- and anisohydric conifer species. Plant, Cell Environ 37:2577-2586

Mendoza I, Gómez-Aparicio L, Zamora R, Matías L (2009a) Recruitment limitation of forest communities in a degraded Mediterranean landscape. J Veg Sci 20:367-376

Mendoza I, Zamora R, Castro J (2009b) A seeding experiment for testing tree-community recruitment under variable environments: implications for forest regeneration and conservation in Mediterranean habitats. Biol Conserv 142:1491-1499

Morin X, Thuiller W (2009) Comparing niche- and processbased models to reduce prediction uncertainty in species range shifts under climate change. Ecology 90:1301-1313

Moser B, Kipfer T, Richter S, Egli S, Wohlgemuth T (2015) Drought resistance of Pinus sylvestris seedlings conferred by plastic root architecture rather than ectomycorrhizal colonisation. Ann For Sci 72:303-309

Padilla FM, Pugnaire FI (2007) Rooting depth and soil moisture control Mediterranean woody seedling survival during drought. Funct Ecol 21:489-495

Paula S, Ojeda F (2009) Belowground starch consumption after recurrent severe disturbance in three resprouter species of the genus Erica. Botany 87:253-259

Plaut JA, Wadsworth WD, Pangle R, Yepez EA, Mcdowell NG, Pockman WT (2013) Reduced transpiration response to precipitation pulses precedes mortality in a piñon-juniper woodland subject to prolonged drought. New Phytol 200:375-387

Polley HW, Johnson HB, Mayeux HS, Tischler CR, Brown DA (1996) Carbon dioxide enrichment improves growth, water relations and survival of droughted honey mesquite (Prosopis glandulosa) seedlings. Tree Physiol 16:817-823

Quero JL, Sterck FJ, Villar R, Martínez-Vilalta J (2011) Water use strategies of six co-existing Mediterranean woody species during a summer drought. Oecologia 166:45-57

Richardson DM, Bond WJ (1991) Determinants of plant distribution: evidence from pine invasions. Am Nat 137:639-668

Richter S, Kipfer T, Wohlgemuth T, Guerrero CC, Ghazoul J, Moser B (2012) Phenotypic plasticity facilitates resistance to climate change in a highly variable environment. Oecologia 169:269-279

Ruiz-Benito P, Gómez-Aparicio L, Zavala MA (2012) Large scale assessment of regeneration and diversity in Mediterranean planted pine forests along ecological gradients. Divers Distrib 18:1092-1106

Ruiz-Benito P, Lines ER, Gómez-Aparicio L, Zavala MA, Coomes DA (2013) Patterns and drivers of tree mortality in Iberian forests: climatic effects are modified by competition. PLoS ONE. doi:10.1371/journal.pone.0056843

Sánchez-Salguero R, Navarro-Cerrillo RM, Camarero JJ, Fernández-Cancio Á (2012) Selective drought-induced decline of pine species in southeastern Spain. Clim Change 113:767-785

Sheffield J, Wood EF (2008) Projected changes in drought occurrence under future global warming from multi-model, 
multi-scenario, IPCC AR4 simulations. Clim Dyn 31:79-105

Taeger S, Sparks TH, Menzel A (2015) Effects of temperature and drought manipulations on seedlings of scots pine provenances. Plant Biol 17:361-372

Tyree MT, Zimmermann MH (2002) Xylem structure and the ascent of sap. Springer, Berlin

Valladares F, Aranda I, Sánchez-Gómez D (2004) La luz como factor ecológico y evolutivo para las plantas y su interacción con el agua. In: Valladares F (ed) Ecología del Bosque Mediterráneo en un Mundo Cambiante. Ministerio de Medio Ambiente, EGRAF, SA, Madrid, pp 335-369

Villar-Salvador P, Puértolas J, Cuesta B, Peñuelas J, Uscola M, Heredia-Guerrero N, Benayas JMR (2012) Increase in size and nitrogen concentration enhances seedling survival in Mediterranean plantations. Insights from an ecophysiological conceptual model of plant survival. New For 43:755-770
Villar-Salvador P, Uscola M, Jacobs DF (2015) The role of stored carbohydrates and nitrogen in the growth and stress tolerance of planted forest trees. New For 46:813-839

Voltas J, Lucabaugh D, Chambel MR, Ferrio JP (2015) Intraspecific variation in the use of water sources by the circum-Mediterranean conifer Pinus halepensis. New Phytol 208:1031-1041. doi:10.1111/nph.13569

Warren CR, McGrath JF, Adams MA (2001) Water availability and carbon isotope discrimination in conifers. Oecologia 127:476-486

Way D, Oren R (2010) Differential responses to changes in growth temperature between trees from different functional groups and biomes: a review and synthesis of data. Tree Physiol 30:669-688

Zweifel R, Steppe K, Sterck FJ (2007) Stomatal regulation by microclimate and tree water relations: interpreting ecophysiological field data with a hydraulic plant model. J Exp Bot 58:2113-2131 